\section{IREATMENT IN THE TOXAEMIAS OF PREGNANCY.}

GILBERT I. STRACHAN, M.D., M.R.C.P.,

LATE RESIDENT OBSTETRICIAN, THE ROYAL GLAGGOW MATFRNITY AND WOMEN'S HOSPITAL ; LATE RESIDENT GXNAECOLOGIST, THE WESTERN INFIRMARY, GLASGOW.

THE exact pathology. of the various toxaemias of pregnancy, although so searchingly investigated of recent yeat's, is still obscure, and for this reason alone treatment can hardly be expected to be perfect in the present state of knowledge; yet it is essential that these conditions should be thoronghly met, as none in all obstetrics are more serious, either imnediately or remotely. In this paper I wish to refer to the treatment of only the fully developed conditions-hyperemesis, albuminuria, eclampsia and the like-but it must constantly be kept in mind that this is only second best, no matter how successful the result may be. Best of all is prevention. 'This view is becoming daily more generally accepted by the profession, and even by the lay public, and it is reasonable to expect a lesser indidence of these oonditions in the future.

For various reasons, however, these cases are often not presented for treatment until the toxaemia is fully developed, and then the most active measures are required to successfully combat the disease. Treatment must always rest on the basis that the woman is pregnant, and that therefore, if the pregnancy be ended, the origin of the toxaemia will be removed. If the pregnancy is to be terminated, this must be done sufficiently early, and not put of until the patient be in danger of losing her life.

Another point ariging out of the previous considerations is that the treatment of these various toxaemias may, and indeed must, run on similar lines, the vatiations being minor and according to special circumstances. This is especially true because at present it is quite uncertain how far these various conditions are separate entities or merely manifertations, different in degree or character, of the one diseage.

If we classify methods of treatment as on the one hand palliative and on the other radical and operative. it will be seen that the individual variations of treatment will occur mainly in the palliative classes, the radical or operative weasures practically resolving themselves into the emptying of the uterus.

In eclampsia sedatives are urgently indicated on account of the flts. On this all are agreed, but not on the ind: vidual sedative or dosage. Morphine, the most potent of these drugs, is probably the best if properly used, although Bumm and Jardine are averse to it; but Williams, 'I'weedy, Galabin, Eden, and especially Stroganoff, strongly recommend it. Galabin gave no more than 2 grains in twenty-four hours, while 'Tweedy administered it until the respirations oame down to seven per minute. A satisfactory and safe routine in my experienoe is to give $\frac{1}{4} \mathrm{gr}$. or $\frac{1}{2} \mathrm{gr}$. at first, to repeat, if necessary, the smaller dose in two hours, and, again if necessary, after another two hours, but not to give more than thiee doses unless some special indication be present. Usually a most satisfactory result will be abtained in this way; if not, more active measures, probably operative, will be called for.' The reasons put torward for its use are that it decreases metabolism and so puts the metabolic sources out of action; that it decreases cerebral irritability and so lessens the fits and the tendency to them; and that it lowers blood pressure while not depressing the heart. Its impairment of excretion and its lamaging effect on kidney tissue are held by some to be contraindications to its use, but if it be used with care as above described, and only for a limited period, I have never seen any harmful results accrue from its administration.

Chloroform is used by many, and in its proper place is certainly of much value. 'Tweedy and Ward $^{1}$ are rather averse to it; they find a similarity between hepatic lesions in eclampsia and those after prolonged administration of chloroform, and the latter likens its administration to the indiscriminate giving of antipyretics in a case of pyrexia without looking to the cause. Its continued use over a lengthened period is much to be deprecated. I have no loubt as to its deleterious effects on the kidneys under these circumstances; but as an adjuvant to operative treatment it still remains unequatlet.

Chloral hydrat; and potassium bromide are of more use for the restlessness between fits than for actual convulsions Stroganoff gives them alternately with morphine, and with this method a death-rate of only 6 per cent. is recorded. Personally I have never seen from these drugs alone any real sedative effect in eclampsia.

Very different is paraldehyde, which almost always I have found of much sedative value and absolutely safe. Two drachms given by the rectum, with repetition of half that dose every two hours when necessary, is usually equal to the largest dose of morphine in this respect, and without any of its contraindications. In my opinion the valuable sedative and safe properties of this drug are not sufficiently appreciated.

But apart altogether from drugs, much attention must be given to the general surroundings of the patient. A single and complete examination should be made at first, and then the patient should be left alone as much as possible, as it is obvious that so strong a peripheral stimulus as a bimanual pelvic examination may very easily set up fresh fits.

In general terms, then, this side of treatment will resolve itself into the exclusion of every agent thiat can act unduly on the tactile, aural, visual, or other receptor systems, and this will include good nursing, a suitably warmed and darkened room, with constant and experienced attention. 'These conditions are obtained to best advantage in an upper class private house; they obviously cannot be obtained in the slums, while in hospital the bustle of a labour ward is not conducive to rest and peace.

In recent years sedative treatment has been perfected by Stroganoff of Petrograd. The patient is put to bed, the head of the bed being elevated, in a quiet and darkened room; chloroform is given lightly and only actually during fits; morphine and chloral and bromide are given alternatively as sedatives. The patient lies on one side for one hour and is then turned for another hour on to the other side so as to avoid pulmonary congestion, while the head is liung over the end of the bed so as to allow free escape of all mucus from the chest. The stomach and bowel are washed out under chloroform and the patient then left alone as much as possible.

With such treatment Stroganoff reports the remarkably low death-rate of 5 per cent. E. Roth, oi Dresden, treated fifty cases in this way and reported 8 per cent. of deaths, as compared with 19 per cent. by other methods of treatment. The fetal mortality was 18.6 per cent., as against 5.5 per cent. by other methods. These figures would appear to speak strongly in favour of sedative expectancy.

On account of the frequent haemorrhages and the heightened blood pressure found in this condition circalatory sedatives are much used by some authorities. Zinke ${ }^{2}$ advocates veratrum viride; he gives 2 minims of the tincture subcutaneously and repeats it hourly until the pulse falls to 60 . The injection is repeated on any rise of the pulse-rate above that. He reports a maternal deathrate of 15.38 per cent. and a fetal death-rate of 53.38 per cent. In a series of cases not so treated he quotes reathrates of 34 and 45 per cent. respectively; judging from this alone the treatment would seem to improve the mother's chances and to prejudice those of the fetus.

The drug is dangerous, however, and is better omitted if it be used at all frequent small doses should be employed so that its action shall be controlled as much as possible.

The action of the nitrites is too evanescent to be of much value in this connexion. Amyl hydrate is much vaunted as a vaso-dilator by Härle, Marash, Naab, Kobelt and some others, all of whom report improved results after its exhibition. Personally I have never used vaso-dilators; the only possible part they can play in really efficient treatment is so small as to be of no practical value.

But in the other type of toxaemia, manifested especially by such a condition as hyperemesis gravidarum, attention must be directed primarily to the gastro-intestinal Lact, since it is here that the causative toxin acts most strongly and evidently. In these cases, first of all, and in spite of the sickness, the stomach should be washed out; some recommend that one drachm of magnesium sulphate in solution should be left in the stomach after the last washing, but this will usually be found to set up fresh vomiting; it slould be omitted as a routine, and used only in the rare cases in which the stomach will tolerate anything. The bowel must next be thoroughly washed out, and, as far as possible, kept clear, as this channel mav have to be used for feeding purposes. 
As regards diet, it may be necessary to withhold nourishnient of any sort for a day or two, but usuadly rectal alimentation will be borne quite satisfactcrily. The mere peptonizing of milk can hardly now be considered a sufficient procedure. Short and Bywaters ${ }^{3}$ have pointed out, as the result of experiment, that proteins must be broken up, not merely to the peptone stage, but must be compietely hydrolyzed to the amino-acid state before they can we absorbed by the bowel mucous membrane. Prolonged action of the enzyme powder is therefore necessary. The same observers find glucose well absurbed by the rectum and colon, but not so other food radicles.

'Tluese considerations are important when we remember how essential is nourishment to sach patients, and how quickly they emaciate; they may, indeed, in a very short time sink so low as to be beyond any treatment.

In this condition we must alivays from the very first, and no matter how the case may be, keep induction of labour in mind; the tendency is too often to leave it until every palliative drug and method has been found wanting, by which time the patient is often fatally ill, and the deatly is regarded as the result of the operation, whereás it is due really to the failure to operato at the proper time.

Of drugs, the gâstric sedatives - bismuth carbonate, tifucture of opìum, dilute hydrocyanic acid-have a most vatiable action; in some cases they are apparently without effect, while in others their action is quite magical ; often, however, they appear merely to excite further vomiting. We cannot look to drugs for any real help in this disease. In nity experience the gastric sedative most likely to prove effective is dilute hydrocyanic acid in 5 minim doses three titrieś a day.

In all toxaemias elimination of fluids so as to remove the circulating toxirs is safe and rational treatment.

1 have referred to the washing out of stomach and bowel which should be dône in every case of toxaemia in preg. nancy: of purgatives (when they can be retained in hyperentresis) the hydragogues-magnesium sulphate 60 grains daily, or compound jalap powder 90 grains as requiredare good, but for the reasons stated above we must rely mainly on enemata. In an unconscious eclamptic patient croton oil would suggest itself. I have tried it several tirmes, but have found it unsatisfactory and useless. Jurdine reports a case in wbich oedema glottidis followed its exhibition, and he is much opposed to its use.

Diaphoresis I have found of distinct benefit, and I have never seen the extreme collapse described by 'Tweedy. The liot pack, or, when it can be obtained, the hot air bath, are both quite safe if the pulse be carefully watclred. Pilocarpine I have never dared to usé, on account of its lowering and reducing action.

As the toxins are circulating in the blood, it is reasonable to suppose that by blood-letting a certain amount of toxin will be removed, and that if in addition fluid (for example, saline) be introduced in place of the abstracted blood, the remaining toxins will be diluted, while the kialneys will be washed clean of accumulated metabolic débris and stimulated to normal excretion.

All these hopes have been realized in practice, and this line of treatment has been of much value. Jardine, the foremost in this country in this direction, at first used sodium acetate, 40 grains to the pint of water, the solution being at a temperature of $104^{\circ} \mathrm{F}$. He selected this salt on account of its diuretic action, but he and others now use normal saline, and with equally good results.

Where vienesection has been performed $(15$ to $20 \mathrm{fl} . \mathrm{oz}$. may safely be removed in a case of averdge severity) saline, 2 to 3 pints, may be introduced into the vein at the same operation, and it will be fonnd that the distended veins in eclampsia facilitate this procedure; very different is the catse with the collapsed veins which accompany the severe prostration of hyperemesis.

In the less urgent cases the saline may be administered by the rectum, and with admirable results; saline may tlitis be administered continuously. Generalized oedema is usually held to be' a contraindication to transfasion, but in practice I have not found it so; however, if oedema of thế lữgs be present, as evidenced by the presence of dullnês's and râles at the bases, it is better to withhold satine, as this oederna may become aggravated and the patient be literally d'rowned in hier own mucus.

Thè sudateri and very temporary efevation of temperatrire sommetimes seen after transfusion is usaally of no moment practically; it has been attributed to the fluid used being at too high a ternperature, but this explanation is quite insulficient to account for the great majority of cases.

Renal decapsulation, introduced by Edebohls and recommended also by $\mathrm{De}$ Bovis, Stoeckel, Sippel of Frankfurt, Lichtenstein of Leipzig, and others, I do not propose to consider at any lengtl. It is a serious remedy; I have never found the need to employ it, and I can hardly see any justification for such a procedure. The death-rate is bound always to be high, and the operation has, quite properly, never become popular.

It is founded on an entirely theoretical basis-to relieve congestion of the organ-and I can see no object in such a severe manipulation when the induction of labour is almost certain to have an infinitely more beneficial effect. Any value attaching to Sellheim's ' operation of amputation of the breasts - the supposed source of the causative toxin according to this observer-depends probably on the accompanying loss of blood, and cannot seriously be regarded as rational treatment.

The methods considered are all at least unsatisfactory. Mostly they are inefficient to cure. Emptying of the uterus, on the contrary, forms the bedrock of operative procedures in these toxaemias.

In general terms, then, the safe and logical obstetrical rule is to treat toxaemic cases of slight and moderate severity by these described palliative measures at first, but if no inprovement shows within twenty-four hours, and much more if the condition become worse in spite of treatment, we must empty the uterus. When this line of treatment has been decided on the sooner the operation is proceeded with the better for the patient. We must entirely disregard the period of gestation and the question of fetal viability and consider only the interests of the mother. In severe cases the uterus should be emptied at once.

Iir pernicious vomiting Williams ${ }^{5}$ lays stress on the anmonia coeffrcient of the urine, and urges that cases with a low coefficient are almost always hysterical, and should be treated as such, and induction of labour not performed. This is true as a generalization, but it must not be forgotten that such cases by prolonged starvation may develop a high ammonia coefficient. Again, cases of purely hysterical vomiting may die of inanition, and in such cases, everything else failing, induction of labour will be called for purely as treatment for the neurosis. These exceptions to the above rule must al ways be kept in mind.

As regards eclampsia, Bumm ${ }^{6}$ quotes -Seitz, who reports a death-rate of 6.5 per cent. with early delivery, 17.2 per cent. after later delivery, and 28.6 per cent. with purely expectant treatment. Iumm himself found a death-rate of 30 per cent. with expectant treatment, but since 1901 lio has in every case delivered as soon as possible after the first fit, and now reports a mortality of 2 per cent.-truly an altered figure.

These views are supported by Zweifel, Horn, Jardine, Cameron, Munro Kerr, and Wiliams. Hermann, Ballantyne, and especially Stroganoff of Petrograd, still advocate expectant treatment and quote figures to support their beliefs. From a recent observation of almost forty case's of eclampsia I have no hesitation in recommending the emptying of the uterus atter the first fit.

The method used will be governed by several factors, especially the urgency of the case and whether or no parturition is proceeding. In hyperemesis, which usually occurs long before term and not at parturition, the insertion of a bougie between membranes and uterine wall will usually be sufficient, the process being then completed normally and usually quite rapidly. If the cervix be tight or the process slow, moderate and intermittent cervical dilatation will usually answer.

In eclampsia at term parturition usually has set in and may be left to be completed, or if thought fit forceps may be applied to speed the process. But if forceps are used no undue force must be employed or unnecessary speed obtained, as a very severe perineal tear may result, which, as the patient is so likely to be a primipara, will very unfavourably influence her later obstetrical and gynaecological history. But if dilatation be slow (perhaps owing to a tight cervix) and the eclamptic condition is becoming worse, operative cervical dilatation is called for. It is wise to be very chary of sudden dilatation either by hand or by Harris's dilators; I have never failed to observe marked post-operative shock after these methods, and once I saw instant death during the proceduro. 
In my opinion, the best method is to make two or three incisions into the cervix, as Didłrssen advises. This immediately produces full dilatation, and also allows a loss of blood, which is itself of benefit. The incisions should always be stitched up when the intrauterine manipulation js completed. Any necessary intrauterine manipulation may be at once proceeded with. When the cervix is fully dilated, if any operative interference be required version or forceps will usually answer the purpose; the former is especially indicated when speed is necessary-for example, when a fetal heart is heard.

Such methods I have never known to fail to produce satisfactory emptying of the uterus and cure of the toxaemic condition. One operation remains to be discussed - namely, Caesarean section. Möller, Paterson, and Humbert of Strassburg advocate the vaginal route, but the number of cases recorded by each is small-Möller reports only seven. McCann ${ }^{7}$ described a successful case, and reported a mortality of 50 per cent. from the literature. 'The indications he gives for performing the operation in toxaemic conditions are (1) frequent fits, (2) labour not yet commenced, (3) contracted cervix, (4) a moribund mother and a live fetus (a rare combination), (5) pelvic contraction. In 1897 Kettlitz collected 28 cases showing a mortality of 50 per cent.; in 1899 Hillmann collected 40 cases with a mortality of 51 per cent., and in 1903 Streicherein reported 26 cases with a mortality of 31 per cent. From these figures it will be seen that the case mortality is really liuge; in any case the operation aims at saving the child, if necessary at the expense of the mother, and I strongly hold that the reverse should always be our aim. I have never seen Caesarean section performed for eclampsia, and can see no prospect of ever performing it in this connexion except for mechanical reasons.

I present these opinions regarding the treatment of toxaemias complicating pregnancy in no dogmatic spirit, but merely as the considered results of recent clinical observations.

RFFERENCES.
Obstet., March, 1910. 2 Zinke: Los. cit., 1 Ward: Amer. Journ. of Obstet., March, 1910. 2 Zinke Loc. cit. Sellheim: Zent. f. Gyndik., 1911, No. 2, p. 54 . 5 Williams: Johns Hopkins Hospitul Bulletiv, 19.6; Gias, Med. Journ., Decomber, 1912 6 Bumm: Wren. med. Klin., Octaber, 1909. 7 MoCann: Lancet, 1910, vol. ii, p. 787

\section{MALARIA AND DISEASES OF THE EYE. BY}

\section{J. KIRK, M.D.EDIN.,}

OOULGT TO EDINBORGH NATIONAL GERTICE BOARDS: FORMERIY VISITING OPHTHALMIC BURGEON, GOVEHNMENT HOSPITALS, THAMTO BORGEN, GOVELNMEN

Mr excuse for writing this brief note is to attempt to clear up in the light of my own experience the exact position of malaria as an etiological factor in the production of eye disease. The question is of great practical importance at all times, but more so in these days when we have large military forces operating in malarious regions. My attention was specially drawn to this subject during the eight months (1916-17) when I acted as ophthalmic specialist to whe troops in Malta. There I was brought into contact with a very large number of soldiers from the Salonica front infected with malaria. A great many of these presented eye symptoms. Interference with vision and night blindness were common complaints, and were generally regarded not only by the men, but also by their medical olticers, as being directly due to repeated attacks of malaria. On examination, however, it was found that the symptoms in a very large proportion of the cases were explained by latent errors of refraction which pre viously had not given trouble, but now, under the strain of the unaccustomed conditions of sun glare, dust, and exposure, enhanced by the debilitating influences of the malarial poison, had become manifest. The night blindness was invariably associated with and accounted for by annemia. I have found, however, that in tropical countries the hypermetrope seems to be specially liable to this complaint, and a good many of my cases in Malta were associated with this condition. Retinal haemorrhages were seen occasionally. In the examination of the fandus in many hundreds of caseq in malarious countries I never found this symptom at all common. A true malarial retinal haemorrhage does occur in subtertian cases, either as the result of capillary thrombosis following parasitio emboli or as a sequel to definite blood changes of a pernicious nature, coincident with great anaemia, but the haemorrhage in the majority of the cases at Malta was certainly not due to such causes. I have a suspicion that some cases were due to overdosage with quinine in susceptible individuals.

Some American ophthalmologists regard malaria as the cause of much eye trouble, especially in the Southern States, and the statement has been made on the authority of Poncet, who published his results as long ago as 1878 , that eye complications occur in 10 per cent. of malarial cases. My experience, as the result of twenty years' practice in a country where a vast amount of malaria was seen, does not coincide with these authorities. Eye complications in malaria appeared to be rare, yet the disease is credited with causing conjunctivitis, keratitis, corneal ulceration, iritis, ratino-choroiditis, optic neuritis, opacities of vitreous and lens, nerve paralysis, retinal haenorrhages, etc. It is easy to make such wide and inclusive statements and difficult to disprove them. I would like to point out, however, that all these symptoms occur as frequently in districts in the tropics where malarial infection is not common as in parts where malaria is rife. They appear to be caused by the intense sun glare, dust and heat, the presence of such complicating conditions as trachoma, gouorrhoea and syphilis, debility, bad hygiene, and such intercurrent diseases as. dysentery-especially the bacillary variety - a common cause of corneal troubles and iritis. In hospital practice in Penang, where the bulk of the patients were either Tamils or Chinese, though both natimalities were equally exposed to and frequently the subject of severe malaria, it was among the former race that the largest amount of such climatic eye troubles was seen. For instance, the Kling is very subject to all the forms of keratitis and corneal ulceration, night blindness, xerosisconjunctivitis, optic atrophy of a primary chronic nature, non-specific, and probably due to malnutrition and chronic anaemia. All this is understandable, for the Kling is often an individual of poor physique and low resisting power and will not feed himself properly. The Chinaman, on the other hand, is a person of much vitality and good physique, though he takes all the malaria that is going. The cause of eye trouble in the Kling is, in the great majority of cases, malnutrition, degenerations, and ensuing secondàry infections.

What we have to regard as almost certainly due to the direct action of the malarial poison are the following:

1. What is commonly called keratitis dendritica is simply a sequel to a herpes of the cornea, and due to a direct action of the malarial poison on the ganglion trophic cells of the fifth nerve. An exactly similar condition occurs quite frequently in influenza, and is due probably to a similar cause. I saw several cases of this in Malta among soldiers infected with malaria. A practical point is that quinine will not help in this condition unless the cause is diagnosed at the very beginning of the attack and energetic quinine treatment started immediately. Once the disease has a firm hold on the cornea and degenera. tive changes have occurred, general treatment does not appear to help, yet it will most certainly do so in the beuinning.

2. A similar poisoning of nerve elements by the direct action of malaria results in external muscle paralysis. The third, fourth, and sixth nerves may be affected, more commonly, in my experience, the sixth.

3. A malarial neuralgia affecting the branches of the ophthalmic division of the fifth is common and may produce reflex conjunctival inflammation, but a puie malarial conjunctivitis would be difficult to diagnose.

As regards the deeper structures, I have never diagnosed malarial iritis or cyclitis or choroiditis. Neuro-retinitis may arise as a complication in malignant and subtertian cases and may be succeeded by nerve atrophy and blind. ness; and I have also seen a retrobulbar neuritis which appeared to be of malarial origin. Haemorrhage from the retinal vessels occur's under the conditions I have already mentioned.

Probably the truth of the matter as to the action of the malarial fevers in producing eye disease is that the parasites or their products have no direct power of producing inflammatory results in the eye structures and this is in accordance with what happens elsewhere in other organs), but they have the power of affecting the 